\title{
A Study to Assess Career Satisfaction among Dental Practitioners in Kanpur City, U.P., India
}

BACKGROUND: For almost every health worker, job satisfaction is an important determinant for motivation, retention and performance, and all of these are primarily important to improve the functioning mechanism of health systems in countries of low-and middle income categories.

AIM: This study was conducted to estimate the level of job satisfaction among registered practicing clinical dentists in Kanpur city, U.P. India

MATERIALS \& METHOD: A cross sectional study was conducted among 204 practicing registered dentists. A questionnaire was distributed manually to the participating dentists for measuring dimensions of job satisfaction. A 5 point Likert format with a score range from 1 (described as strongly dissatisfied) to 4 (described as strongly satisfied) was used to describe the items. Analysis of data was analyzed using SPSS software 21.0 and student $t$ test was applied for measuring the difference of means between the subgroups for each dimension. RESULTS: A significant difference $(\mathrm{p}<0.005$ ) in levels of satisfaction for various dimensions of job satisfaction within gender, educational qualification and work status was found on analysis. The postgraduates were found to be more satisfied as compared to graduates with a difference in job satisfaction level between genders which was related to the personal time dimension. It was also derived from the study that dentists working full time expressed dissatisfaction in terms of family time, thus to issues in their personal relationships.

CONCLUSION: Overall, it was found that the dentists have a high level of job satisfaction and the socio demographic factors deeply influence this domain of career.

KEYWORDS: Career, Job, Satisfaction, Practice, Dentists

\section{INTRODUCTION}

Satisfaction is said to be associated with motivation or attitude, or may be a result of the psychosocial working environment. Health, performance and satisfaction at work is deeply influenced by factors like work environment, workers' needs and skills, working conditions of the organization, culture and personal choice. ${ }^{1}$ Career satisfaction has been previously defined as the "positive emotional state resulting from the appraisal of one's job or job experience, and is related to many aspects of patient care and outcomes of health system as well as to contentment in general life and job related performance. ${ }^{2}$ The speedy random changes in healthcare services and policies, have increased the rate of job dissatisfactions among the healthcare professionals. Job gratification can stress on better organizational commitments of workers, which indirectly speeds up the overall success and progress of the organization and decreases the levels of intentions that provoke the employees to quit their association with the organization. Professional satisfaction, salaries, delivery of care, respect and job timings are also significantly associated with job satisfaction.3 Those workers who are dissatisfied are more prone to leave the organization and this impacts the thoughts of the staying workers who might show poor performances and may also sabotage the targets and quit their roles from the job. 4

Dentistry provides is a unique social interaction influenced by specific demands of the clinical practice, exposure to an intimate and very sensitive area of the human body, personal characteristics and emotions of a health care provider and its recipient. ${ }^{5}$ Over the years, research has identified dentistry as being one of the most stressful professions, with high levels of workrelated stress linked to poor working relationships and low job satisfaction. ${ }^{6}$ Researchers have also reported that pressure due to time-bound work, heavy workloads, financial issues, anxious and difficult patients, problems with staff, limitation of the resources, poor conditions at workplace and the monotonous nature of the job are the most common provoking factors. ${ }^{7}$ A high turnover of dentists and dental auxiliaries may result from low job comfort that further may result in productivity loss and quality of care while treating patients. ${ }^{2}$

A variety of factors may influence fulfilment in the job and there have been a number of international studies examining dentist job satisfaction and job stressors but 
levels of job satisfaction among dentists practicing in private and public sectors, difference between male and female genders as well as among graduates and post graduates are still some of the key issues to be assessed. Dentists' job satisfaction can be enhanced by finding out and getting some indication in the existence of any systematic variation in levels of satisfaction governed by these factors. Hence, the main reason behind the present study was to assess career satisfaction among registered dentists who are practicing in Kanpur city, Uttar Pradesh (U.P.), India.

\section{MATERIALS AND METHODS}

Study setting and design: A cross sectional study was conducted among 220 dental registered practicing dentists.

Ethical clearance: Ethical approval was received from the institutional review board. The informed consent was obtained from all the dentists participating in the survey.

The questionnaire used in this research was taken from a study conducted by Rebecca V. Harris in the year 2008. ${ }^{8}$ This is a 28 -item questionnaire concerning questions regarding staff, personal time, intrinsic satisfaction, community where dentist is working, compensation, administrative responsibilities and available resources. The participants indicated their perception level of agreement or disagreement along with the concerned statements on a 5-point Likert scale with ' 1 ' indicating strong disagreement (strong dissatisfaction) and ' 5 ' indicating strong agreement (strong satisfaction).

A pilot study was conducted on 20 study participants to pretested the questionnaire followed by assessing the reliability of the questionnaire by using Test-Retest. The measured value of Kappa (k) and Weighted Kappa were found to be 0.86 and 0.9 respectively. Internal consistency of the questionnaire was assessed by applying Chronbachs-Alpha (á) and the value 0.78 was measured. The dentists were selected from register of Indian Dental Association of Kanpur branch and each dentist was approached by the study Investigator at their clinic for requesting their participation in the survey. Dentists who consented their participation were given a print copy of the questionnaire in person and were requested to respond back within 15 days. They were also explained about the study design. Selected dentists were given gentle reminders through phone calls before the deadline. Out of 220, 204 completed the questionnaire giving the response rate of $89 \%$ and thus subjects who were non-contactable $(6 \%)$ and filled incomplete questionnaire $(5 \%)$ were excluded from the study. Statistical analysis: All the collected data were entered in Microsoft excel and analyzed using the SPSS 21 version for descriptive and inferential statistics. The mean weighted scores and Standard deviation were calculated for each dimension of job satisfaction based on responses to the items of each dimension. To analyze the difference of means between the subgroups for each dimension, the student $t$ test was used. For the present study, the confidence interval was fixed at $95 \%$.

\section{RESULTS}

Table 1 describes the characteristics of the population. A total of 204 dentists completed the questionnaire out of which $50.53 \%$ were postgraduates and rest $(49.47 \%)$ were graduates. Over $23.4 \%$ of respondents reported working in sector. There were less female study participants as compared to males.

The overall mean dimension/sub-scale scores for Job satisfaction (weighted mean data) are shown in Table 2. The three highest mean scores reported by dentists were for the autonomy, personal time and administrative responsibility (Table 2).

While examining mean job satisfaction scores for each dimension/sub-scale of gender, female dentists reported a higher average score compared to male dentists in a personal time dimension(3.09 \pm 0.88 ) whereas the male showed significant difference values in the autonomy $(2.87 \pm 0.9)$ and administrative responsibilities dimensions $(2.83 \pm 1.13)$. (Table 3 )

There were significant differences seen as expressed by graduate and post graduate dentists in relationships with colleagues $(2.01 \pm 0.98)$, patients $(2.99 \pm 1.44)$ and intrinsic satisfaction $(3.45 \pm 0.92)$ and thus represented that the post graduate practitioners were more gratified with their jobs as compared to graduates. (Table no. 4)

Table 5 shows the differences in mean scores of the nine dimensions of the job satisfaction scale by work status defining the number of hours spend by the practitioners at practice. Full time dentists reported feeling more adequately met with their devotion of time to the patients and work as compared to the services provided by part time dentists. However, dissatisfaction in the time spent with their family was also documented by full time dentists who also reported to suffer from 


\begin{tabular}{|c|c|c|c|}
\hline CHARACTERISTICS & & $\mathbf{N}$ & $\%$ \\
\hline Age group & $\begin{array}{c}25-34 \text { years } \\
35-44 \text { years } \\
45-54 \text { years } \\
55 \text { above }\end{array}$ & $\begin{array}{l}21 \\
63 \\
13 \\
10\end{array}$ & $\begin{array}{c}19.63 \\
59 \\
12.02 \\
9.35\end{array}$ \\
\hline Gender & $\begin{array}{l}\text { Male } \\
\text { Female }\end{array}$ & $\begin{array}{l}54 \\
53\end{array}$ & $\begin{array}{l}51.6 \\
48.4\end{array}$ \\
\hline Area of practice & $\begin{array}{c}\text { General practice (BDS) } \\
\text { Registered specialist practice (MDS) } \\
\text { Public sector practice (Govt. Hospitals) }\end{array}$ & $\begin{array}{l}38 \\
45 \\
24\end{array}$ & $\begin{array}{c}33.6 \\
43 \\
23.4\end{array}$ \\
\hline $\begin{array}{l}\text { Educational } \\
\text { Qualification }\end{array}$ & $\begin{array}{l}\text { Graduate } \\
\text { Postgraduate }\end{array}$ & $\begin{array}{l}53 \\
54\end{array}$ & $\begin{array}{l}49.53 \\
50.47\end{array}$ \\
\hline Work-status & $\begin{array}{l}\text { Full-time (working for }>50 \text { hours /week) } \\
\text { Part-time (working for }<50 \text { hours /week) }\end{array}$ & 58 & $\begin{array}{l}53 \cdot 7 \\
46.3\end{array}$ \\
\hline $\begin{array}{l}\text { Geographic region } \\
\text { (where they are } \\
\text { practicing) }\end{array}$ & $\begin{array}{l}\text { Metropolitan } \\
\text { Non-metropolitan }\end{array}$ & $\begin{array}{l}48 \\
59\end{array}$ & $\begin{array}{r}44.86 \\
55.14\end{array}$ \\
\hline
\end{tabular}

Table 1. Characteristics of Respondents

\begin{tabular}{|c|c|c|}
\hline $\begin{array}{l}\text { JOB SATISFACTION } \\
\text { DIMENSIONS }\end{array}$ & NO. OF ITEMS & $\mathbf{M E A N} \pm \mathbf{S D}$ \\
\hline Autonomy & 3 & $2.35 \pm 0.9$ \\
\hline Relationships with colleagues & 2 & $1.95 \pm 0.87$ \\
\hline Relationships with patients & 6 & $2.32 \pm 1.12$ \\
\hline Relationships with staff & 2 & $2.02 \pm 0.76$ \\
\hline Personal time & 2 & $2.79 \pm 1.15$ \\
\hline Intrinsic satisfaction & 5 & $2.32 \pm 0.88$ \\
\hline Community & 3 & $1.79 \pm 1.31$ \\
\hline Administrative responsibilities & 2 & $2.81 \pm 0.9$ \\
\hline Resources & 3 & $2.03 \pm 1.03$ \\
\hline Total & 28 & $20.38 \pm 0.75$ \\
\hline
\end{tabular}

Table 2. Overall Mean Dimension/Sub-Scale Scores for Job Satisfaction

the work burden leading to issues in their personal relationships. There are a number of domains in the practice of dentistry that can lead to the development of satisfaction or dissatisfaction among the practicing dentists. Job satisfaction has also been discussed in relation to issues like high staff turnover, potential productivity loss resulting from turnover and movement away from the dental stream totally. ${ }^{2}$

\section{DISCUSSION}

In the present study, an overall measure of achievement in the profession indicated that dentists were reasonably satisfied with their job. Satisfaction scores were higher for autonomy, resources and relationships with staff, patients and colleagues, but lower for personal time, compensation and administrative duties and these findings are in line with the results of a study done by Jeong $\mathrm{SH}$ in $2006^{9}$ who suggested that patient relations, personal time, staff, perception of income, and specialty training are important factors at working place for job satisfaction. Similar results were also reported previously in 2005 by Luzzi $\mathrm{L}^{2}$ who showed significantly lower mean scores for six out of ten dimensions of job satisfaction, namely community, autonomy, relationships with patients and staff, compensation and resources. Male and female dentists showed significant differences on certain dimensions like personal time and administrative responsibilities with female dentists reporting higher scores in the personal time dimension which measured happiness 


\begin{tabular}{|c|c|c|c|}
\hline JOB SATISFACTION DIMENSIONS & MALE $($ MEAN \pm SD) & FEMALE (MEAN \pm SD) & p-VALUE \\
\hline Autonomy & $2.87 \pm 0.9$ & $2.31 \pm 0.92$ & $0.002^{*}$ \\
\hline Relationships with colleagues & $1.87 \pm 0.93$ & $2.09 \pm 1.02$ & 0.25 \\
\hline Relationships with patients & $2.31 \pm 1.19$ & $2.86 \pm 1.41$ & 0.03 \\
\hline Relationships with staff & $2.0 \pm 0.76$ & $2.08 \pm 0.85$ & 0.61 \\
\hline Personal time & $2.45 \pm 1.02$ & $3.09 \pm 0.88$ & $0.002^{*}$ \\
\hline Intrinsic satisfaction & $2.29 \pm 0.9$ & $2.4 \pm 0.89$ & 0.53 \\
\hline Community & $1.78 \pm 0.9$ & $1.85 \pm 0.93$ & 0.69 \\
\hline Administrative responsibilities & $2.83 \pm 1.13$ & $2.01 \pm 1.16$ & $0.0003^{*}$ \\
\hline Resources & $2.01 \pm 0.74$ & $2.11 \pm 0.69$ & 0.47 \\
\hline
\end{tabular}

Table 3. Job Satisfaction Dimension/Sub-Scale Mean Scores by Gender

\begin{tabular}{|c|c|c|c|}
\hline JOB SATISFACTION DIMENSIONS & $\begin{array}{l}\text { GRADUATES } \\
(\text { MEAN } \pm S D)\end{array}$ & $\begin{array}{c}\text { POSTGRADUATES } \\
(\mathrm{MEAN} \pm \text { SD) }\end{array}$ & p-VALUE \\
\hline Autonomy & $2.01 \pm 0.91$ & $2.96 \pm 0.95$ & $<0.0001^{*}$ \\
\hline Relationships with colleagues & $1.94 \pm 0.98$ & $2.01 \pm 0.98$ & 0.78 \\
\hline Relationships with patients & $2.2 \pm 1.17$ & $2.99 \pm 1.44$ & $0.0023^{*}$ \\
\hline Relationships with staff & $2.01 \pm 0.78$ & $2.07 \pm 1.02$ & 0.7 \\
\hline Personal time & $3.03 \pm 0.95$ & $2.45 \pm 1.02$ & $0.003^{*}$ \\
\hline Intrinsic satisfaction & $2.38 \pm 0.894$ & $3.45 \pm 0.92$ & $<0.0001^{*}$ \\
\hline Community & $1.76 \pm 0.90$ & $2.45 \pm 0.93$ & $0.0002^{*}$ \\
\hline Administrative responsibilities & $2.88 \pm 1.11$ & $2.78 \pm 1.17$ & 0.65 \\
\hline Resources & $2.07 \pm 0.71$ & $2.47 \pm 0.73$ & $0.005^{*}$ \\
\hline
\end{tabular}

Table 4. Job Satisfaction Dimension/Sub-Scale Mean Scores by Educational Qualification

\begin{tabular}{|c|c|c|c|}
\hline $\begin{array}{c}\text { JOB SATISFACTION } \\
\text { DIMENSIONS }\end{array}$ & $\begin{array}{c}\text { FULL TIME } \\
(\text { MEAN } \pm \text { SD) }\end{array}$ & $\begin{array}{c}\text { PART TIME } \\
(\text { MEAN } \pm \text { SD) }\end{array}$ & p-VALUE \\
\hline Autonomy & $2.35 \pm 0.89$ & $2.45 \pm 0.94$ & 0.74 \\
\hline Relationships with colleagues & $1.94 \pm 0.94$ & $2.01 \pm 1.03$ & 0.71 \\
\hline Relationships with patients & $2.29 \pm 1.19$ & $2.42 \pm 1.23$ & 0.58 \\
\hline Relationships with staff & $2.04 \pm 0.73$ & $2.04 \pm 0.89$ & $>0.99$ \\
\hline Personal time & $2.06 \pm 0.93$ & $2.68 \pm 0.99$ & $0.0002^{*}$ \\
\hline Intrinsic satisfaction & $2.85 \pm 0.88$ & $2.38 \pm 0.92$ & $0.0081^{*}$ \\
\hline Community & $1.04 \pm 0.53$ & $1.9 \pm 0.96$ & $<0.0001^{*}$ \\
\hline Administrative & $2.88 \pm 1.15$ & $2.79 \pm 1.13$ & 0.68 \\
\hline responsibilities & & & 0.78 \\
\hline Resources & $2.04 \pm 0.69$ & $2.08 \pm 0.76$ & \\
\hline
\end{tabular}

Table 5. Job Satisfaction Dimension/Sub-Scale Mean Scores by Work Status

with quality and quantity of time to self and family. Similar results have been found in study done in 2005 by Berdahl and Anderson ${ }^{10}$ suggesting that women prefer more egalitarian roles, whereas men feel more comfortable in a hierarchical situation, and women work better in collaborative work teams than do men. It has been also reported in various studies that male and female dentists differ in their working patterns and career satisfaction and female dentists work significantly fewer hours than male dentists. Also find themselves trying to balance the conflicting demands of a professional career and family responsibilities and hence family commitments tend to be the reason for more women dentists working part-time. ${ }^{11-12}$ 
The post-graduation qualification obtained by completing masters in dental surgery has a strong consequence on contentment among the dentists. Thereby, higher mean scores were reported in all of the dimensions for job satisfaction except for the relationships with colleagues and staff.

The limitation of this study was that it did not include dentists who were no longer practicing or who had left practice and so as a result mean satisfaction scores may be higher. This study also does not explain the levels of satisfaction according to age difference as it has been observed that dentists who were practicing for longer duration that is who were older would be more satisfied with various aspects of their job compared to their younger counterparts. Also the old aged dentists may be in the peak of the demands placed on them by their dental career and may find themselves under increased stress and pressure associated with building and sustaining a viable practice.

This study has thus revealed that there are various dimensions of fulfilment at work place that may be pertinent to issues impacting on recruitment and retention of dentists in active clinical practice. In the present study, dentists indicated high levels of satisfaction with similar factors (such as autonomy, resources and relationships with staff, patients and colleagues) so these aspects of dentistry could be used to promote the profession to boost recruitment, especially given there is evidence to suggest they play an influential role in the choice to pursue dentistry as a career. Relationship with patients, colleagues and staff can contribute to job satisfaction by developing an effective and stable dental team. The areas of dissatisfaction such as personal time and administrative responsibilities need to be addressed in order for any recruitment campaigns to be effective, and also to retain those already working in dentistry.

This study gives insights into the diverse dimensions of job satisfaction highlighting better job satisfaction among the postgraduate dental professionals. The issue of job satisfaction among the practicing dentist need to be addressed in society to improve recruitment and retention rates of dentists in active clinical practice in different sectors of the dental care system. Workplaces that offer job autonomy, competitive remuneration, flexible working hours and minimum administrative burden may improve dentist job satisfaction. Educational programs should be directed to help professionals to cope with their professional duties without hazardous effects on their physical and mental health.

\section{REFERENCES}

1. Loretto NRM, Coelho AFC, Gutenberg L, Coelho TMC. Job Satisfaction among Dental Assistants in Brazil. Braz Dent J. 2013 ; 24(1): 53-8.

2. Luzzi L, Spencer AJ, Jones K, Teusner D .Job satisfaction of registered dental practitioners. Aust Dent J 2005;50(3):179-85.

3. Gilmour J, Stewardson DA, Shugars DA, Burke FJ. An assessment of career satisfaction among a group of general dental practitioners in Staffordshire. Br Dent J 2005;198:701-704.

4. Seraj B, Ghadimi S, Mirzaee M, Ahmadi R, Bashizadeh H, Ashofteh-Yazdi K et al. Job Satisfaction and its Influential Factors in Dental Academic Members in Tehran, Iran. Ann Med Health Sci Res. 2014;4(2): 1927.

5. Puriene A, Aleksejuniene J, Petrauskiene J, Balciuniene I, Janulyte V . Self-perceived Mental Health and Job Satisfaction among Lithuanian Dentists. Ind Health 2008; 46:247-52.

6. Luzzi L, Spencer AJ . Job satisfaction of the oral health labour force in Australia. Aust Dent J 2011; 56: 23-32.

7. Ayers KM, Thomson WM, Newton JT, Rich AM. Job stressors of New Zealand dentists and their coping strategies. Occup Med. (London) 2008;58:275-81.

8. Harris RV, Ashcroft A, Burnside G, Dancer JM, Smith D, Grieveson B. Facets of job satisfaction of dental practitioners working in different organizational settings in England. Br Dent J. 2008 Jan 12;204(1):1-8

9. Jeong SH, Chung JK, Choi YH, Sohn W, Song KB. Factors related to job satisfaction among South Korean dentists. Community Dent Oral Epidemiol. 2006 Dec;34(6):46o-6.

10. Brake H, Bloemendal E, Hoogstraten J. Gender differences in burnout among Dutch dentists. Community Dent Oral Epidemiol.2003 Oct;31(5):321-7. 11. Ayers KM, Thomson WM, Rich AM, Newton JT. Gender differences in dentists' working practices and job satisfaction. J Dent. 2008;36(5):343-50.

12. Berdahl JL, Anderson C. Men, women, and leadership centralization in groups over time. Group Dyn Theor Res. 2005; 9:45-7. 
Source of support: Nil, Conflict of interest: None declared

Cite this article as:

Seth N, Goel S, Yadav S. A Study to Assess Career Satisfaction among Dental Practitioners in

Kanpur City, U.P. India. Int Healthc Res J. 2019;3(6):211-216.

https://doi.org/10.26440/IHRJ/0306.09292

\section{AUTHOR AFFILIATIONS:}

1. $\quad$ MDS (Public Health Dentistry), Consultant Dental Surgeon and Ex-Senior Lecturer, Department of Public Health Dentistry, Ambedkar Dental College, Patna, Bihar, India. [(ORCID ID: https://orcid.org/oooo-ooo1-8148-3232),(Corresponding Author)]

2. $\quad$ MDS (Periodontics), Consultant Dental Surgeon \& Private Practitioner.

3. BDS, Private Practitioner, Shri Ji Dental Clinic, Koyala Nagar, Kanpur.

Contact corresponding author at: nikhilster166[at]gmail[dot]com 